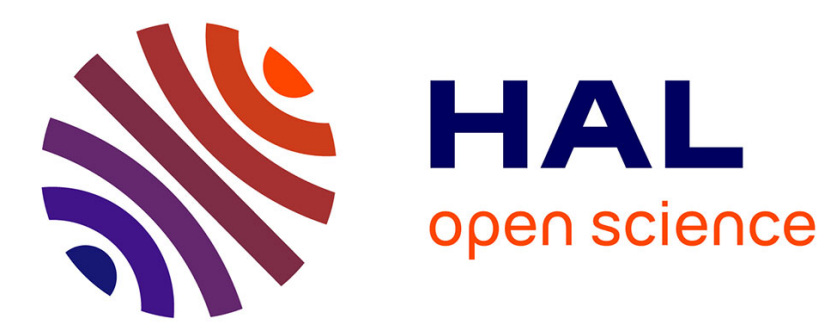

\title{
DISLOCATION KINETICS OF SHOCK WAVE METAL DEFORMATION
}

\author{
L. Merzhievsky, A. Tyagel'Sky
}

\section{To cite this version:}

L. Merzhievsky, A. Tyagel'Sky. DISLOCATION KINETICS OF SHOCK WAVE METAL DEFORMATION. Journal de Physique IV Proceedings, 1991, 01 (C3), pp.C3-525-C3-531. 10.1051/jp4:1991374 . jpa-00250519

\section{HAL Id: jpa-00250519 https://hal.science/jpa-00250519}

Submitted on 1 Jan 1991

HAL is a multi-disciplinary open access archive for the deposit and dissemination of scientific research documents, whether they are published or not. The documents may come from teaching and research institutions in France or abroad, or from public or private research centers.
L'archive ouverte pluridisciplinaire HAL, est destinée au dépôt et à la diffusion de documents scientifiques de niveau recherche, publiés ou non, émanant des établissements d'enseignement et de recherche français ou étrangers, des laboratoires publics ou privés. 
Colloque C3, suppl. au Journal de Physique III, Vol. 1, octobre 1991

\title{
DISLOCATION KINETICS OF SHOCK WAVE METAL DEFORMATION
}

\author{
L.A. MERZHIEVSKY and A.V. TYAGEL'SKY \\ Lavrentyev Institute of Hydrodynamics, Siberian Division \\ of the USSR Academy of Sciences, Novosibirsk 630090, USSR
}

\begin{abstract}
A construction is made for the dislocation metal deformation kinetics in a shock wave, that takes into account, besides the traditional dislocation multiplication mechanisms, the mechanism of heterogeneous dislocation nucleation on point defects. The applicability of kinetics for modelling the shock wave processes in metals is shown.
\end{abstract}

\section{I - INTRODUCTION}

Among the models applied to describing behaviour of metals under shock loading, the ones based on the representations of physical irreversible (plastic) deformation mechanisms is of special interest. As such physical mechanism, the dislocation ensemble dynamics is considered, beginning from papers by J.J. Gilman and J.W. Taylor [1, 2 ]. Papers [1, 2], their numerous versions and modifications give us a complete detailed analysis of behaviour peculiarities of plane shock waves and rarefaction ones in metals. They were used for consideration of the elastoplastic wave splitting effects, the elastic precursor attaining of the stationary regime, the shock wave amplitude decay at interaction with an overtaking rarefaction wave, the free surface motion at emergence of the shock wave on it and a possibility of the spalling, etc. It is easy to generalize formally a well-developed one-dimensional variant of the models for the general three-dimensional case [3], however, lack of the experimental data on dislocation ensemble evolution under dynamic loading, that are required for constructing more general models, discourages wide use of the dislocation models. Introduction of the dislocation representations of the irre- 
versible deformation into a continuum model [4] to describe dynamic deformation of metals is one of the ways of their use extension developed by the authors of this paper in previous studies. The other way is construction of more accurate kinetic equations describing the dislocation ensemble dynamics. In this paper, the dislocation kinetics is built, that allows a description of the additional dislocation multiplication mechanisms characteristic of the shock wave processes.

It is appropriate to mention here that it is not a success to describe a series of experimentally registered effects if to take into account only the dislocation nucleation and multiplication mechanisms observed under quasistatic conditions and to use real values of the dislocation density. To show an agreement of the experimental results with the calculated ones, it is often required to introduce an initial number of dislocations exceeding by $2-3$ orders that one obtained in quasistatic experiments, or deliberately to overvalue considerably the dislocation multiplication coefficient in the dislocation kinetics equation used in the model [2, 5]. This is, apparently, due to that the other mechanisms called heterogeneous $[6,7]$ act under shock compression in addition to usually considered mechanisms of dislocation multiplication (the Frank-Read sources, the double cross-gliding) [1]. The existence of these heterogeneous mechanisms is shown by calculations of the crystal lattice behaviour under shock compression with the help of the molecular dynamics method [5].

\section{II - KINETICS WITH ALIOWANCE FOR HETEROGENEOUS DISLOCATION NUCLEATION}

The plastic deformation is assumed to be due to the dislocation motion in the planes of the main shear stresses that coincide with the planes of the main plastic strains. The plastic strain value of $\gamma$ is connected with the dislocation ensemble characteristics by relation

$$
\gamma=\mathrm{b} \cdot \mathrm{N} \cdot \mathrm{l} \text {, }
$$

where b is the Burgers vector; $\mathrm{N}=\mathrm{N}(\tau, \gamma, \dot{\gamma})$ is the dislocation density; $l=1(\tau, \gamma, \dot{\gamma})$ is the average dislocation displacement. Here $\tau, \dot{\gamma}$ are the main shear stress and plastic strain rate, respectively, on the given plane of gliding. The time differentiation of equation (1) gives the expression for the plastic strain rate

$$
\dot{\gamma}=\mathrm{b} \cdot \dot{\mathrm{N}} \cdot \mathrm{l}+\mathrm{b} \cdot \mathrm{N} \cdot \mathrm{v},
$$

where $\mathrm{v}$ is the average velocity of the dislocation motion along the given plane of gliding. The first summand in (2) is often neglected, this relation is used in the form of the orowan relation

$$
\dot{\gamma}=\mathrm{b} \cdot \mathrm{N} \cdot \mathrm{v}
$$

although it is clear that under the shock loading the value of $\dot{N}$ can be too high. The construction proposed in this paper is based on the complete relation (2). Following [1], further consideration is usually given to the mechanisms controlling a number of dislocations and mobile ones during the shock compression process. They are

- dislocation multiplication with the help of a fixed number of the Frank-Read sources;

- dislocation multiplication by multiple cross-gliding;

- dislocation fixing that results in strain hardening. 
If the dominant dislocation multiplication mechanism is the stationa-

ry Frank-Read sources, then

$$
\dot{\mathrm{N}}=\text { const, }
$$

hence,

$$
\mathrm{N} \sim \sqrt{\gamma}
$$

The experimental results evidence in favour of the other mechanism, i.e. the multiple cross-gliding [1], in this case

$$
\dot{\mathrm{N}} \sim \mathrm{N} \text {, }
$$

hence,

$$
\mathrm{N}(\gamma)=\mathrm{N}_{0}+\mathrm{M} \cdot \gamma
$$

where $\mathrm{N}_{0}$ is the initial number of dislocations, $M$ is the multiplication coefficient. The non-zero contribution into the change of $\gamma$ in the second summand of the right-hand part of equation (2) is provided only by the mobile dislocations, whose number $\mathrm{N}_{\mathrm{m}}$ is established in

[1] on the basis of the account for the strain hardening

$$
\mathrm{N}_{\mathrm{m}}=\mathrm{N} \cdot \exp \left[-\frac{\mathrm{H} \cdot|\gamma|}{|\tau|}\right]
$$

where $H$ is the strain hardening coefficient, $\tau$ is the maximum shear stress. On the basis of results of the analysis made in [8], for describing the average velocity of the dislocation motion, let's take the dependence

$$
\mathrm{v}=\mathrm{v}_{0} \cdot \exp \left(-\frac{\mathrm{D}}{\mid \tau T}\right) \cdot \operatorname{sign}(\tau)
$$

where $v_{0}$ is the maximum possible dislocation motion velocity that is equal to the shear wave velocity, $D$ is the characteristic drag stress. The value of 1 is the average distance run by the dislocation during the loading process till the moment of its stop near an obstacle or before emergence on the free specimen surface, the mentioned value being strongly dependent on the loading conditions and structural peculiarities of the material. Systematical data on the influence of either parameter on 1 are absent. The average displacement is assumed to change proportionally to the size of a dislocation cell, formed during deformation, with the dislocation structure evolution [9]. In this case

$$
1 \sim a / \sqrt{\mathrm{N}}
$$

where the constant a is to be defined from the experimental data. According to different estimates $[10]$, we have that

$$
10^{-3} \mathrm{~cm} \geqslant 1 \geqslant 10^{-5} \mathrm{~cm} \text {. }
$$

For taking into account a possibility of heterogeneous dislocation nucleation in the shock front, we'Il use the findings from [5] that concern the role of point defects in such process. According to [5], the intersticial atoms and the substitutional ones forming the zones 
of local internal compression stress can be the efficient shear nuc lei, as well as the inclusions having the less compressibility coefficient than the basic material. The data obtained in [5] allow us to connect the change of a dislocation number with the parameters characterizing the shock compression $\varepsilon=2 \gamma, \sigma, \tau_{m}$, where $\sigma$ is the stress behind the plane shock front on a square that is perpendicular to direction of the shock propagation, $\tau_{m}$ is the maximum shear stress in the shock front. At least, the expansion of appearing aislocation loops occurs in the shock front, therefore it is logic that these dislocations are referred to the mobile ones. As the simplest satisfactory approximation of data from [5] the following expression can serve, that has the form

$$
\mathrm{N}_{\mathrm{ms}}=\mathrm{N}_{\mathrm{mo}} \cdot|\gamma|^{\alpha} \cdot|\tau|^{\beta}
$$

$\left(\mathrm{N}_{\mathrm{ms}}\right.$ is the density of formed dislocations, $\mathrm{N}_{\mathrm{mo}}, \alpha, \beta$ are the constants) and is taken as a dependence of the dislocation density change due to their heterogeneous nucleation. Actually, the heterogeneous nucleation mechanisms begin working at attaining the critical values of $\gamma$ and $\tau$ during the shock compression process. However, in the given variant of the dislocation kinetics this circumstance is neglected. This is thought to be warranted if further (7) is considered to be used along with (4), (3). It should be noted that for the known [7, 11] attempts of taking into account a possibility of heterogeneous dislocation nucleation, the linear relation of $\mathbf{N}_{\mathrm{ms}}$ with $\tau$ is arbitrarily assumed. Thus, for the kinetics proposed, the full dislocation density

$$
\mathrm{N}=\mathrm{N}_{0}+\mathrm{M} \cdot \gamma+\mathrm{N}_{m 0} \cdot|\gamma|^{\alpha} \cdot|\tau|^{\beta}
$$

and the density of mobile dislocations

$$
\mathrm{N}_{\mathrm{m}}=\mathrm{N} \cdot \exp \left(-\frac{\mathrm{H} \cdot|\gamma|}{|\tau|}\right)
$$

In rather powerful shock waves $\mathrm{N}-\mathrm{N}_{\mathrm{ms}}$. Table presents some values, characterizing the dislocation ensemble deformed under shock compression in iron, in accordance with the calculation data from [5] and on kinetics proposed in [1] and in this paper. The values in Table have the following dimensional representation: $\tau_{\max }, \sigma-\mathrm{GPa}, \mathrm{N}_{\mathrm{m}}-\mathrm{cm}^{-2}$.

\section{TABLE}

\begin{tabular}{|c|c|c|c|c|c|c|c|}
\hline & \multicolumn{3}{|c|}{$[5]$} & \multicolumn{3}{c|}{ present paper } & {$[1]$} \\
\hline$\gamma$ & $\sigma$ & $\tau_{\max }$ & $\mathrm{N}_{\mathrm{m}}$ & $\sigma$ & $\tau_{\max }$ & $\mathrm{N}_{\mathrm{m}}$ & $N_{\mathrm{m}}$ \\
\hline 0.025 & 10 & 1 & $10^{10}$ & 6.7 & 0.2 & $10^{10}$ & $2.5 \cdot 10^{9}$ \\
\hline 0.10 & 50 & 10 & $10^{12}$ & 48.4 & 6.3 & $10^{12}$ & $10^{10}$ \\
\hline 0.15 & 100 & 20 & $10^{13}$ & 122.8 & 25.4 & $10^{13}$ & $2 \cdot 10^{10}$ \\
\hline
\end{tabular}




\section{III. - CALCULATION RESULTS}

The applicability of dislocation kinetics is usually validated by comparing the experimental data and results of solution of the problems on propagation and evolution of plane shock waves in metal specimens. The main system of the corresponding equations expressing the conservation laws, that are general for any media, and the Hooke law was derived in [1, 2] and quoted many times in different works. The system is added by kinetic relations (2), (5), (6), (8) and (9). The problem is solved numerically by a finite difference "cross" scheme. The schemes without strong discontinuity tracking are usually introduced by the artificial viscosity that allows the solution on function discontinuities to be found. In calculations presented the artificial viscosity is not introduced, since it turned out that the approximation viscosity and physical one owing to the plastic relaxation of an elastic wave are almost sufficient for obtaining a continuous solution.

As in a majority of the analogous papers, the problems have been solved in this paper on formation of the two-wave structure of an elastoplastic shock wave due to separation of an elastic precusor and its attaining of the stationary level and on the shock wave decay at its interaction with an overtaking rarefaction wave. It should be noted that with the help of the dislocation kinetics proposed earlier the adequate quantitative description of these two processes at the same time, without changing the constants entering the kinetics, was not a success. In solving the first problem, the loading was simulated by prescribing the constant mass velocity value of $u=50 \mathrm{~m} / \mathrm{s}$ on the region boundary; in the second problem, collision of two thicknessdifferent plates with a velocity of $100 \mathrm{~m} / \mathrm{s}$ was calculated. To give a possibility of comparing the calculated and experimental results [1, 2], iron was chosen as the material of plates. The results of solution of the first problem are shown in Figs.1, 2; and Figs. 3, 4, 5 present those of the second problem solution.

Figures 1, 2 illustrate the calculation profiles of the mass velocity and quantity of mobile dislocations for different time moments as the shock wave advances into the specimen. The points and curve 1 in Fig. 1 show the experimental data [2] on the elastic precusor amplitude decay. The calculated and experimental results agree fairly well. It is necessary to point to one peculiarity of the calculated profiles that is also available in the papers by other authors. This peculiarity is the presence of a spike on the elastic precusor front. As the spike, the effect of solution oscillation in the vicinity of the discontinuity, that is well-known to specialists on numerical methods, is wrongly taken. This effect is due to the value of the approximation and artificial viscosity that is insufficient for suppressing disturbances (see, for example, [12]). A comparison of the disturbance amplitude with the physical value of the upper yield point is noncorrect.

Figures 3, 4, 5 present the results of calculation of the overtaking rarefaction wave interaction with the shock front. The striking plate thickness is $0.15 \mathrm{~cm}$ in this case. On the profiles of velocity (Fig. 4) the formation of the two-wave configuration is observed both in the shock wave and rarefaction one. After rarefaction, the gislocation density in the material remains essentially higher $\left(>10^{8} \mathrm{~cm}\right.$ against $\mathrm{N}_{0}=10^{6} \mathrm{~cm}$, than the initial one. This manifests itself under reloading in the form of a well-known Bauschinger effect. 

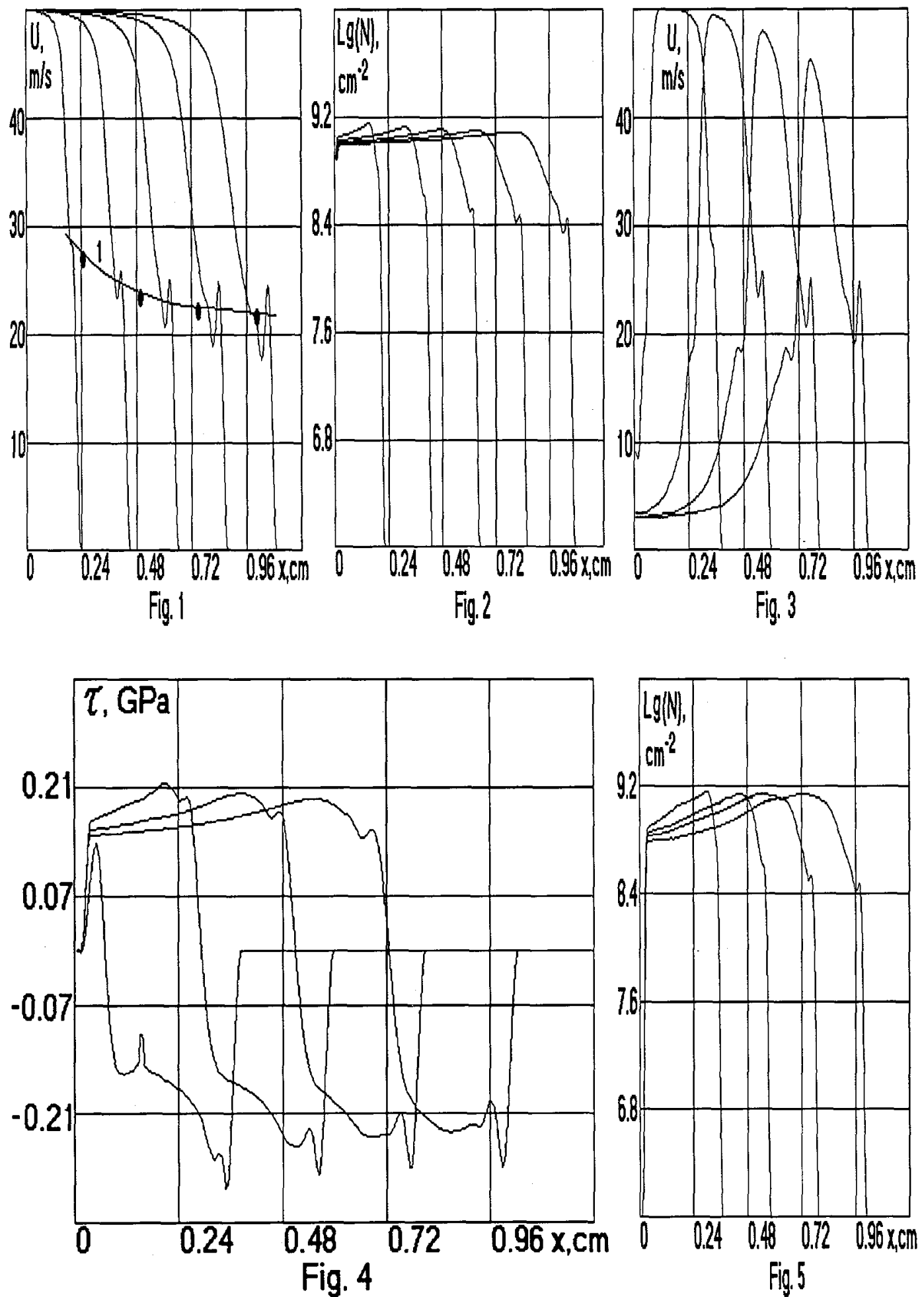

Fig. 4 


\section{IV. - CONCLUSION}

In this paper the dislocation kinetics of metal deformation in a shock wave has been proposed, that takes into account, besides the traditional dislocation multiplication mechanisms, the mechanism of heterogeneous dislocation nucleation on point defects. This allows description of the shock processes in metals to be made using the real values of characteristics of the initial dislocation ensemble and not those known to be overestimated.

\section{REFERENCES}

1. Gilman J.J. Appl. Mech. Rev. 21 (1968) 8, 767.

2. Taylor J.W. Journ. of Appl. Phys. 36(1965) 10, 3146.

3. Merzhievsky L.A. Dinamika sploshnoi sredy, Novosibirsk (1983) 59, 158 .

4. Merzhievsky L.A., Tyagel'sky A.V. Journ. de Physique 49(1988) 9, 457.

5. Mogilevsky M.A., Mynkin I.O. Fizika goreniya i vzryva 14(1978) 5,159 .

6. Asay J.R. et al. Journ. of Appl. Phys. 43(1972) 5, 2132.

7. Asay J.R. et al. Journ. of Appl. Phys. 46(1975) 10, 4316.

8. Bukayemsky A.A., Merzhievsky L.A. Dinamika sploshnoi sredy, Novosibirsk (1987) 80, 31 .

9. Holt D.L. Journ. of Appl. Phys. $41(1970) 8,3197$.

10. Murr L.E. Scripta Met. $12(1978)$ 2, 201.

11. Gupta Y.M. Journ. of Appl. Phys. 46(1975) 2, 532.

12. Rozhdestvensky B.L., Yanenko N. N. Systems of quasilinear equations and their application to gas dynamics. Moscow, Nauka (1968) 592 . 